\title{
Predisposing Factors of Community Acquired Pneumonia in Under-Five Children
}

Preeti Srivastava, Asit Kumar Mishra* and Ashish Kumar Roy

Department of Paediatrics, Tata Main Hospital, Jamshedpur, India

\begin{abstract}
Objective: Pneumonia is a leading cause of mortality and morbidity in under five children in developing countries. Hence, the present study was undertaken to identify the various predisposing factors for pneumonia in children aged 1 month to 5 years.

Methods: Sixty pneumonia cases fulfilling the inclusion criteria, in the age group of 1 month to 5 years were interrogated for potential predisposing factors as per a predesigned proforma. Sixty healthy control children in the same age group were also interrogated.
\end{abstract}

Results: The significant predisposing factors for pneumonia were overcrowding ( $p$ value $<0.001$ ), lack of exclusive breastfeeding for first 6 months in babies less than 1 year old ( $p$ value $<0.05$ ), incomplete immunization for age ( $p$ value $<0.001$ ) and malnutrition ( $p$ value $<0.001)$. On logistic regression analysis, overcrowding and malnutrition were significant independent risk factors.

Conclusion: The present study has identified many demographic, nutritional and environmental pre-disposing factors for pneumonia which can be tackled by effective health education of the community and appropriate initiatives taken by the government.

Keywords: Pneumonia; Breastfeeding; Immunization; Overcrowding; Malnutrition

\section{Introduction}

Despite dramatic advances in human health, under 5 mortality remains alarmingly high. UNICEF in statistics on child mortality have shown that every year, almost 10.5 million children die before their fifth birthday; i.e., 30,000 children every day! Half of the deaths in under 5 children can be directly attributed to just 5 diseases-pneumonia, diarrhoea, malaria, measles and AIDS [1]. Pneumonia kills more children than AIDS, malaria and measles combined and that effective interventions exist to prevent and treat pneumonia but the coverage of these interventions remains too low. Pneumonia control is therefore a priority and is essential in achieving Millennium Development Goal Four, which calls for a reduction by two-thirds in the under-five mortality rate by 2015 [2].

The International Consultation on Control of Acute Respiratory Infections, December 1991, reported that there are links between environmental risk factors [such as; smoke, outdoor air pollution, indoor pollution, passive smoking, overcrowding] and risk factors in the child [that is low birth weight, malnutrition, measles, breastfeeding and vitamin A deficiency] with acute respiratory infections. Many of these risk factors are amenable to corrective measures. Therefore knowledge of these risk factors related to acquisition of Acute Lower Respiratory Infections (ALRI) will help in its prevention. Therefore, the following study was undertaken to identify the various predisposing factors of community acquired pneumonia in fewer than five children.

\section{Material and Methods}

This was a prospective case-control study conducted in Paediatrics Department of Tata Main Hospital, Jamshedpur. The study was conducted over a period of one year from March 2013 to February 2014. All cases and controls were selected from the age group of 1 month to 5 years if they fulfilled the inclusion criteria. Inclusion criteria for cases were that the child should have clinical features of pneumonia as per WHO criteria [3], on chest radiogram, the child should have features compatible with pneumonitis as reported by a qualified radiologist and the child should be admitted as in-patient. Exclusion criteria for cases were features of tuberculosis or mantoux positivity, features of severe sepsis, clinical diagnosis of asthma [based on history of repeated episodes of wheeze with rapid response to bronchodilator therapy, positive family history of bronchial asthma] and any underlying chronic illness. Controls were selected from out-patient department. Inclusion criteria for controls were presence of features of Upper Respiratory Tract Infection (URTI) for example blocked nose, congested throat, rhinorhea, child should not have pneumonia as per WHO criteria and chest $\mathrm{x}$-ray should be normal. Exclusion criteria for controls were same as those for cases.

Verbal informed consent of the child's caregiver was obtained in both cases and controls. Relevant history was taken and detailed physical examination was done for both cases and controls. Questionnaire (as per predesigned proforma) was presented to both groups where information about the potential risk factors were sought after like presence of overcrowding; history of exclusive breast feeding for first six months of life; history of smoking in the family; immunization status especially DPT, measles and Hib ; protein energy malnutrition and features of vitamin A deficiency.

Overcrowding was considered to exist if the number of persons in the household divided by the rooms in the dwelling exceeded the accepted standards which are as follows $[1$ room -2 persons; 2 rooms - 3 persons; 3 rooms -5 persons; 4 rooms -7 persons; 5 or more -10 persons (additional 2 for each further room)]. A baby under 12 months was not counted; children between 1 to 10 years were counted as half a unit. Overcrowding was also considered to exist if 2 persons over 9

${ }^{*}$ Corresponding author: Asit Kumar Mishra, Department of Paediatrics, Tata Main Hospital, Jamshedpur, India, Tel: 9204657193; E-mail: drasitmishra@gmail.com

Received October 26, 2015; Accepted December 13, 2015; Published December 20,2015

Citation: Srivastava P, Mishra AK, Roy AK (2015) Predisposing Factors of Community Acquired Pneumonia in Under-Five Children. Lung Dis Treat 1: 101. doi:10.4172/2472-1018.1000101

Copyright: @ 2015 Srivastava P, et al. This is an open-access article distributed under the terms of the Creative Commons Attribution License, which permits unrestricted use, distribution, and reproduction in any medium, provided the original author and source are credited. 
years of age, not husband and wife, of opposite sex were obliged to sleep in same room [4].

History of smoking by various family members was recorded. History of exclusive breastfeeding for first six months was taken. Vitamin A deficiency was identified and graded according to WHO classification of Xeropthalmia [X1A - conjunctival xerosis, X1B - bitot's spot, X2 - corneal xerosis, X3A- corneal ulceration ( $<1 / 3$ of cornea), $\mathrm{X} 3 \mathrm{~B}$ - corneal ulceration ( $>1 / 3$ of cornea), $\mathrm{XN}$ - night blindness, $\mathrm{XF}$ fundal changes, XS - corneal scarring ].

Weight (in kilograms) for age (in months) was recorded for both cases and controls and then compared to the expected weight for that age as per CDC growth charts (year-2000). Malnutrition was identified and graded according to Indian Academy of Paediatrics (IAP) classification [weight of more than $80 \%$ of expected for age is normal. Grades of malnutrition are Grade I (71-80\%), II (61-70\%), III (51$60 \%)$, IV $(<50 \%)$. History of immunization was elicited from parents and verified by checking the documents wherever available.

The predisposing factors were then tabulated in both the groups and statistically analyzed. The study was previewed and approved by the ethical committee of Tata Main Hospital, Jamshedpur.

\section{Statistical methods used}

Chi square test was used to calculate the $P$ value of each predisposing factor. P value $<0.05$ was considered significant. $\mathrm{P}$ value $<0.001$ was considered highly significant. Data was further analyzed by Logistic Regression Methods using the SPSS version 17.0.

\section{Results}

In this study, 60 cases of pneumonia were compared with 60 controls (cough and cold). Majority of children were infants with their age distribution comparable between the two groups with male preponderance in both the groups. The majority of children with pneumonia were infants less than 1 year of age (61.67\%; Table 1$)$. There were more male children affected with pneumonia than females $(68.33 \%$ vs. $31.67 \%$; Table 1).Each pre disposing factor was analyzed separately for statistical significance (Table 1). Overcrowding was significantly associated with pneumonia [ $85 \%$ (cases) vs. $26.67 \%$ (controls); 'p' value $<0.001]$. Lack of exclusive breastfeeding wasn't significantly associated with pneumonia [ $30 \%$ (cases) vs. $35 \%$ (controls); 'p' value $>0.05$ ] when all the children between 1 month to 5 years were considered. However on further analyzing the data considering only children less than 1 year old among cases and controls, it was observed that lack of exclusive breastfeeding [51.35\% (cases) vs. $22.58 \%$ (controls); 'p' value $<0.05$ ] was significantly associated with pneumonia. Presence of family history of smoking [ $70 \%$ (cases) vs. $60 \%$ (controls); 'p' value $>0.05$ ] was not statistically significant. In our study incomplete immunization for age was significantly associated with pneumonia [ $80 \%$ (cases) vs. $38.33 \%$ (controls), 'p' value $<0.001]$.In our study incomplete immunization for age was significantly associated with pneumonia [ $80 \%$ (cases) vs. $38.33 \%$ (controls), 'p' value $<0.001]$.Further, on separately analyzing the association of pneumonia with DPT, Measles and Hib vaccination, it was seen that DPT and Measles immunization was not significantly associated with pneumonia as $78.33 \%$ of cases and $83.33 \%$ of controls had received DPT vaccine and $84 \%$ of cases and $85.7 \%$ of controls had received Measles vaccine. However there was a considerable difference in the number of children who received Hib vaccination among cases and controls (20\% vs. $61.67 \%)$. Thus there was a significant association between lack of Hib vaccination and pneumonia ( $\mathrm{p}<$ 0.001 ).Malnutrition, present in $71.67 \%$ of cases as compared to $11.67 \%$ of controls, was significantly associated with pneumonia ('p'< 0.001$)$.
Vitamin A deficiency was not significantly associated with pneumonia.

On reanalyzing the data using logistic regression methods (Table 2), overcrowding and malnutrition emerged to be significant independent risk factors for acquiring community acquired pneumonia in under five children ( $\mathrm{p}$ value being $<0.05$, at $95 \%$ confidence level).

\section{Discussion}

The majority of children with pneumonia were infants less than 1 year of age $(61.67 \%)$ with more male children affected with pneumonia than females $(68.33 \%$ vs. $31.67 \%$; Table 1).In a study by Saurav Chatterjee, it was seen that age specific attack rate of ARI decreased with increasing age of the child in both sexes and the worst sufferers were in the age group 6-11 months in both sexes, but considering all the age groups, sex specific attack rates were more in males than in females [5].

Overcrowding contributes to the transmission of infection through respiratory droplet. In our study, overcrowding was significantly associated with pneumonia. This was in agreement with a study by Cardoso et al. where it was seen that crowding was associated with a $60 \%$ reduction in the incidence of asthma but with $21 / 2$-fold increase in the incidence of lower respiratory tract infections $(p=0.001)$ [6].

The critical role of breast-feeding in improving infant and under-five-year survival in resource-limited settings has been well documented since the mid-1970s. A pooled analysis by the World Health Organization (WHO) of a number of studies on the impact of breast-feeding on child survival showed that the protective effect is strongest in the first six months of life, with a 4-6-fold survival benefit for breast-fed infants. The benefit extends throughout the first year of life, with a 1.4-1.8-fold protective effect against mortality during months six through twelve [7]. In this study, when children less than 1 year of age were only considered, lack of exclusive breastfeeding [ $51.35 \%$ (cases) vs. $22.58 \%$ (controls); 'p' value $<0.05$ ] was significantly associated with pneumonia. Similarly, in a study by Shams Arifeen et al. it was observed that partial or no breastfeeding was associated with a 2.40 fold higher risk of deaths attributable to ARI [8].

Environmental tobacco smoke (ETS) is one of the indoor air pollutants that reduces local defence mechanisms and predisposes children to respiratory illness [9]. In our study, presence of family history of smoking [ $70 \%$ (cases) vs. $60 \%$ (controls); Table 1; 'p' value $>0.05$ ] was not statistically significant. Our result was in concordance with another study by Savitha MR et al. [10]. Wieslaw Jedrychowski and Elzbieta Flak in their study found strong evidence that children exposed to ETS in their homes were more susceptible to acute respiratory tract illnesses than unexposed children [11]. However in our study there was no history of maternal smoking (either in ante-natal or post-natal period) both among the cases and controls. No significant association of pneumonia with passive smoking in our study could be due to low ETS exposure level as majority of smokers in the families were fathers and the exposure of children due to smoking by fathers was limited because of relatively greater time spent by fathers outside the house.

In our study incomplete immunization for age was significantly associated with pneumonia [ $80 \%$ (cases) vs. $38.33 \%$ (controls), Table 1 ; 'p' value $<0.001]$. Similar results were found by Broor et al. [12] and M.R. Savitha et al. [10]. This is probably because mothers utilizing these services are better aware of health care facilities and probably seek early consultation for illness of their children, which probably avoids severe illness. In another study by DK Agarwal et al. on rural preschool children, it was observed that the moderate and severe ARI related morbidity and mortality was significantly reduced in immunized 
Citation: Srivastava P, Mishra AK, Roy AK (2015) Predisposing Factors of Community Acquired Pneumonia in Under-Five Children. Lung Dis Treat 1: 101. doi:10.4172/2472-1018.1000101

Page 3 of 4

\begin{tabular}{|c|c|c|c|c|}
\hline SI. no. & Variables & Pneumonia cases $(n=60)$ & $\begin{array}{l}\text { Controls } \\
(n=60)\end{array}$ & 'p' value \\
\hline \multirow[t]{4}{*}{1.} & Age & & & \\
\hline & $<1 \mathrm{yr}$ & $37(61.67 \%)$ & $31(51.67 \%)$ & \\
\hline & $1-3 \mathrm{yr}$ & $12(20 \%)$ & $19(31.67 \%)$ & \\
\hline & $3-5 \mathrm{yr}$ & $11(18.33 \%)$ & $10(16.67 \%)$ & \\
\hline \multirow[t]{3}{*}{2.} & Sex & & & \\
\hline & Male & $41(68.33 \%)$ & $33(55 \%)$ & \\
\hline & Female & $19(31.67 \%)$ & $27(45 \%)$ & \\
\hline \multirow[t]{3}{*}{3.} & Overcrowding & & & \multirow{3}{*}{$<0.001$} \\
\hline & Present & $51(85 \%)$ & $16(26.67 \%)$ & \\
\hline & Absent & $9(15 \%)$ & $44(73.33 \%)$ & \\
\hline \multirow[t]{3}{*}{4.} & Exclusive BF & & & \multirow{3}{*}{$>0.05$} \\
\hline & Present & $39(65 \%)$ & $42(70 \%)$ & \\
\hline & Absent & $21(35 \%)$ & $18(30 \%)$ & \\
\hline \multirow[t]{3}{*}{5.} & Exclusive $\mathrm{BF}$ in < 1yr. & $(n=37)$ & $(n=31)$ & \multirow{3}{*}{$<0.05$} \\
\hline & Present & $18(48.65 \%)$ & $24(77.42 \%)$ & \\
\hline & Absent & $19(51.35 \%)$ & $7(22.58 \%)$ & \\
\hline \multirow{3}{*}{6.} & Family h/o smoking & & & \multirow{3}{*}{$>0.05$} \\
\hline & present & $42(70 \%)$ & $36(60 \%)$ & \\
\hline & Absent & $18(30 \%)$ & $24(40 \%)$ & \\
\hline \multirow{3}{*}{7.} & Immunization for age & & & \multirow{3}{*}{$<0.001$} \\
\hline & Complete & $12(20 \%)$ & $37(61.67 \%)$ & \\
\hline & Incomplete & $48(80 \%)$ & $23(38.33 \%)$ & \\
\hline \multirow{3}{*}{8.} & DPT vaccine & & & \multirow{3}{*}{$>0.05$} \\
\hline & Received & $47(78.33 \%)$ & $50(83.33 \%)$ & \\
\hline & Not received & $13(21.67 \%)$ & $10(16.67 \%)$ & \\
\hline \multirow{3}{*}{9.} & Hib vaccine & & & \multirow{3}{*}{$<0.001$} \\
\hline & Received & $12(20 \%)$ & 37 (61.67\%) & \\
\hline & Not received & $48(80 \%)$ & $23(38.33 \%)$ & \\
\hline \multirow{3}{*}{10.} & Measles vaccine & $(n=25)$ & $(n=35)$ & \multirow{3}{*}{$>0.05$} \\
\hline & Received & $21(84 \%)$ & $30(85.7 \%)$ & \\
\hline & Not received & $4(16 \%)$ & $5(14.23 \%))$ & \\
\hline \multirow{3}{*}{11.} & Malnutrition & & & \multirow{3}{*}{$<0.001$} \\
\hline & Absent & $17(28.33 \%)$ & $53(88.33 \%)$ & \\
\hline & Present & $43(71.67 \%)$ & $7(11.67 \%)$ & \\
\hline \multirow[t]{2}{*}{12.} & Vitamin A deficiency & & & \\
\hline & Present & $2(3.33 \%)$ & Nil & \\
\hline
\end{tabular}

Table 1: Demographic, nutritional and environmental variables in the cases and controls.

\begin{tabular}{|c|c|c|c|}
\hline SI. No. & Factors studied & Odds Ratio & 95\% C.I. \\
\hline 1 & Overcrowding & 15.3023 & $4.6330-50.56$ \\
\hline 2 & Exclusive BF (first 6 months) & 0.8264 & $0.2723-2.5561$ \\
\hline 3 & Passive Smoking & 1.6062 & $0.5112-5.080$ \\
\hline 4 & Complete Immunization for age & 0.4251 & $0.1331-1.354$ \\
\hline 5 & Malnutrition & 17.0551 & 0.4200 \\
\hline
\end{tabular}

Table 2: Predisposing factors for pneumonia using Binary Logistic Regression methods.

children compared to unimmunized children [13]. Further, on separately analyzing the association of pneumonia with DPT, Measles and Hib vaccination, it was seen that DPT and Measles immunization was not significantly associated with pneumonia as $78.33 \%$ of cases and $83.33 \%$ of controls (Table 1 ) had received DPT vaccine and $84 \%$ of cases and $85.7 \%$ of controls (Table 1) had received Measles vaccine. This high coverage of DPT and Measles vaccination was probably due to the fact that this study was conducted in an industrial setting where the family members were strongly motivated about the benefits of immunization and these vaccines were available free of cost at easily accessible immunization centers spread across the town. However there was a considerable difference in the number of children who received Hib vaccination among cases and controls (20\% vs. $61.67 \%$ ), (Table 1). Thus there was a significant association between lack of Hib vaccination and pneumonia $(\mathrm{p}<0.001)$. Our results conform to multiple studies [14-16], which have demonstrated Hib vaccine effectiveness in preventing $\mathrm{x}$-ray confirmed pneumonia. In Kenya, introduction of Hib vaccine into the routine childhood immunization program reduced Hib disease incidence among children aged $<5$ years to $12 \%$ of its baseline level [17].

Overall malnutrition is associated with a two to three fold increase in 
mortality from ALRI [18]. In our study malnutrition, present in $71.67 \%$ of cases as compared to $11.67 \%$ of controls, (Table 1 ) was significantly associated with pneumonia ('p'<0.001). Similar conclusions were drawn in other studies also [10,12]. A study in Philippines included age stratified risks in children less than 23 months of age and reported highest risk of death from ALRI due to malnutrition among those aged 12-22 months [19]. A study in New Delhi revealed severe malnutrition as the predictor of mortality in ALRI in 2 week to 5 years old children [20]. In another study by Shah $\mathrm{N}$ et al. malnutrition was observed to be a significant risk factor on univariate analysis [21].

On reanalyzing the data after multivariate logistic regression analysis (Table 2), overcrowding and malnutrition remained as significant independent risk factors for community acquired pneumonia in under-five children. Overcrowding ( $\mathrm{OR}=15.30 ; 95 \%$ CI: $4.63-50.56$; ' $p$ ' value $=0.00001$ ) had a significant positive association with pneumonia thereby showing that a child with overcrowding is 15 times more likely to develop pneumonia as compared to a child without overcrowding. Similarly in a study by Savitha MR et al. in Mysore, AOR for overcrowding was 11.985 (95\% CI: 2.578-55.720; ' $p$ ' value $=0.002$ ) [10]. Malnutrition (OR=17.06; CI: 4.61-63.08; 'p' value=0.0003) was significantly associated with pneumonia. Similarly, several other studies have shown malnutrition to be significantly associated with pneumonia and its outcome e.g. Broor et al: severe malnutrition ( $\mathrm{OR}=1.85 ; 95 \% \mathrm{CI}$ : 1.14-3.0) [12], Fatmi et al.: malnutrition (wasting) ( $\mathrm{AOR}=2.2,95 \% \mathrm{CI}$ : $1.0,5.23)[22]$ and Savitha MR et al: malnutrition (AOR=6.939; 95\% CI: 1.06-45.29) [10]. In our study, complete immunization for age was not statistically significant ('p' value $>0.05$ at $95 \%$ confidence level) after multivariate regression analysis, though being significant (' $\mathrm{p}$ ' value $<$ 0.001 ) when each factor was analyzed separately (Table 1 ). The reason for this could be that the number of children completely immunized among the cases was very small, 12 out of $60(20 \%)$. So when this variable was adjusted with other covariates, it didn't emerge out to be significant. Although, it can be seen that at $85 \%$ confidence level ( $p<$ 0.15 ), this factor becomes significant. So, if the sample size of the study was increased, it could probably emerge out to be significant.

\section{Conclusions}

The present study identified many pre-disposing factors for pneumonia. Univariate analysis showed that overcrowding, lack of exclusive breast feeding in first year of life, incomplete immunization for age and malnutrition were significantly associated with pneumonia. On logistic regression analysis, overcrowding and malnutrition remained as significant independent risk factors.

The above risk factors can be tackled through effective health education of the community and appropriate initiatives taken by the government leading to a healthy community and a healthy nation as a whole.

\section{Acknowledgement}

We are thankful to our General Manager, Medical Services for allowing us to publish this research work. We are also thankful to all the parents who allowed us to enroll their children in this study.

\section{Conflict of Interest}

The authors declare no conflict of interest regarding the publication of this paper.

\section{References}

1. Choudhury $P$ (2007) Indian pediatrics and child survival. See comment in PubMed Commons below Indian Pediatr 44: 567-568.

2. (2008) UNICEF hails WHO Bulletin: pneumonia major cause of child death New Delhi.
3. World Health Organization (2000) Handbook IMCI. Integrated management of childhood illness. Geneva, Switzerland: World Health Organization.

4. Park K (2002) Environment and Health In Park's Textbook of Preventive and Social Medicine, 17 $7^{\text {th }}$ (Edn), Banarsidas Bhanot Publishers 528.

5. Chatterjee S (2007) A Study Of Epidemiological Factors Related To Acute Respiratory Infection (ARI) In Under Five Children Attending The Immunization Clinic Of Calcutta National Medical College And Hospital. The Internet Journal of Pulmonary Medicine 7: 6.

6. Cardoso MR, Cousens SN, de Góes Siqueira LF, Alves FM, D'Angelo LA (2004) Crowding: risk factor or protective factor for lower respiratory disease in young children? BMC Public Health 4:19.

7. World Health Organization (2000) Effect of breastfeeding on infant and child mortality due to infectious diseases in less developed countries: a pooled analysis. WHO Collaborative Study Team on the Role of Breastfeeding on the Prevention of Infant Mortality. Lancet 355: 451-455.

8. Arifeen S, Black RE, Antelman G, Baqui A, Caulfield L, et al. (2001) Exclusive Breastfeeding Reduces Acute Respiratory Infection and Diarrhea Deaths Among Infants in Dhaka Slums. Pediatrics 108: e67.

9. Victora CG, Smith PG, Barros FC, Vaughan JP, Fuchs SC (1989) Risk factors for deaths due to respiratory infections among Brazilian infants. Int J Epidemiol 18: $918-925$

10. Savitha MR, Nandeeshwara SB, Pradeep Kumar MJ, ul-Haque F, Raju CK (2007) Modifiable risk factors for acute lower respiratory tract infections. Indian J Pediatr 74: 477-482.

11. Jedrychowski W and Flak E (1997) Maternal smoking during pregnancy and postnatal exposure to environmental tobacco smoke as predisposition factors to acute respiratory infections. Environ Health Perspect 105: 302-306.

12. Broor S, Pandey RM, Ghosh M, Maitreyi RS, Lodha R , et al. (2001) Risk factors for severe acute lower respiratory tract infection in under-five children. Indian Pediatr 38: 1361-1369.

13. Agarwal DK, Bhatia BD, Agarwal KN (1993) Simple approach to acute respiratory infection in rural under five children. Indian Pediatr 30: 629-635.

14. Adegbola RA, Secka O, Lahai G, Lloyd-Evans N, Njie A, et al. (2005) Elimination of Haemophilus influenzae type $b(\mathrm{Hib})$ disease from The Gambia after the introduction of routine immunisation with a Hib conjugate vaccine: a prospective study. Lancet 366: 144-150.

15. Levine OS, Lagos R, Muñoz A, Villaroel J, Alvarez AM, et al. (1999) Defining the burden of pneumonia in children preventable by vaccination against Haemophilus influenzae type b. Pediatr Infect Dis J 18: 1060-1064.

16. Gessner BD, Sutanto A, Linehan M, Djelantik IGG, Fletcher T, et al. (2005) Incidences of vaccine-preventable Haemophilus influenzae type B pneumonia and meningitis in Indonesian children: hamlet-randomized vaccine probe trial. The Lancet 365: 43-52.

17. Cowgill KD, Ndiritu M, Nyiro J, Slack MP, Chiphatsi S, et al. (2006) Effectiveness of Haemophilus influenzae type $b$ Conjugate vaccine introduction into routine childhood immunization in Kenya. JAMA 296: 671-678

18. Rice AL, Sacco L, Hyder A, Black RE (2000) Malnutrition as an underlying cause of childhood deaths associated with infectious diseases in developing countries. Bull World Health Organ 78: 1207-1221.

19. Yoon PW, Black RE, Moulton LH, Becker S (1997) The effect of malnutrition on the risk of diarrheal and respiratory mortality in children $<2$ y of age in Cebu, Philippines. Am J Clin Nutr 65: 1070-1077.

20. Sehgal V, Sethi GR, Sachdev HPS, Satyanarayana L (1997) Predictors of mortality in subjects hospitalized with acute lower respiratory tract infections. Indian Pediatr 34: 213-218.

21. Shah N, Ramankutty V, Premila PG, Sathy N (1994) Risk factors for severe pneumonia in children in south Kerala: a hospital-based case-control study. J Trop Pediatr 40: 201-206.

22. Fatmi Z, White F (2002) A comparison of 'cough and cold' and pneumonia: risk factors for pneumonia in children under 5 years revisited. Int J Infect Dis 6: 294-301. 